\section{The Dea[r]th of Human Understanding}

Neville Holmes, University of Tasmania
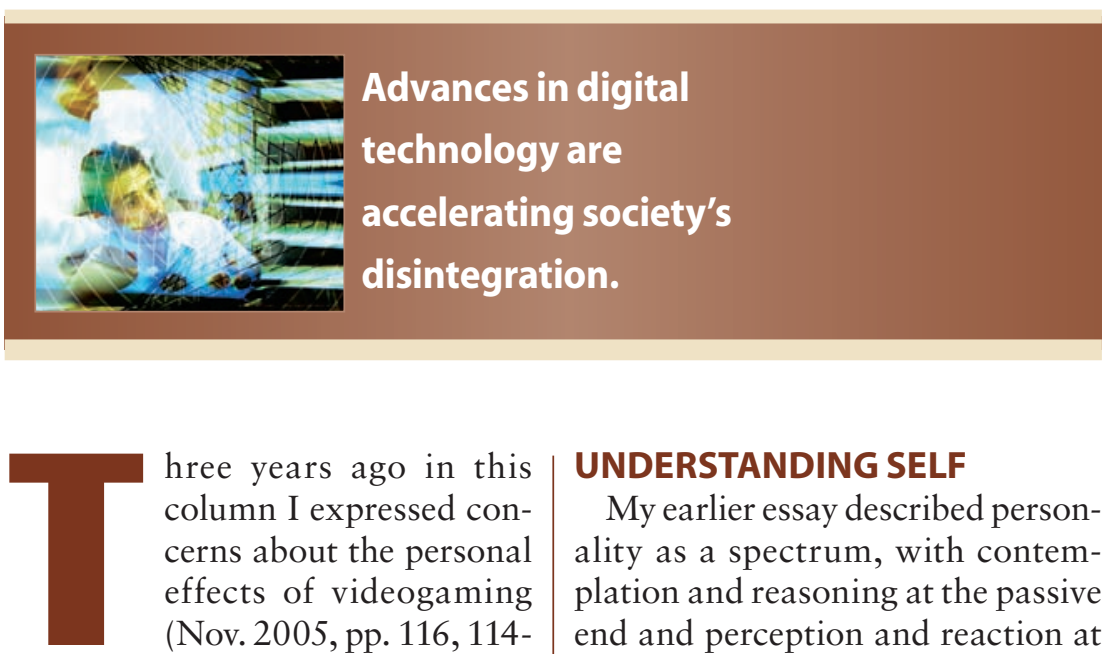

hree years ago in this column I expressed concerns about the personal effects of videogaming (Nov. 2005, pp. 116, 114115). Since then, those concerns have grown. Recent reading suggests that my previously described concerns are too narrow and that the increasing use of digital technology is having a widespread and degrading influence on humanity.

Raising dangerous issues of this kind is not a technical activity. Rather, it embodies the personality, attitudes, and values of the person raising the issues. The effect that raising such issues has on any reader will depend greatly on that reader's personality, attitudes, and values. But the issues are about the effects of digital technology on such attributes.

Avoiding this circularity requires appealing to the responsibility of computing professionals to consider the social effects of their technology. This responsibility is laid down in the IEEE's Code of Ethics (www. ieee.org/portal/pages/iportals/ aboutus/ethics/code.html).

\section{UNDERSTANDING SELF}

My earlier essay described personality as a spectrum, with contemplation and reasoning at the passive end and perception and reaction at the active end. Book reading pushes personality toward passivity, while videogaming pushes personality toward activity. Well-rounded personalities are toward the middle of the spectrum.

\section{Personality is key}

Personality governs behavior. Neurological considerations suggest that purely active personalities are primitive. Much of behavior is automatic. Sensations are unconsciously dealt with by neural processes that feed perceptions into the site of consciousness, where reactive decisions are made that other neural processes unconsciously convert into behavior (The Profession, May 2002, 112, 110-111). Repeated decisions can become automatic reactions.

Conversion of perception into reaction is common to all animal life. Simple animals seem to react entirely automatically, and we are reluctant to consider them as having minds and conscious behavior. More complex animals cannot be denied the possession of minds and consciousness.

Humans have often been thought of as distinct from lower animals, as having a different kind of mind. Neuroscientists no longer believe this. The human brain merely has a large capacity for storing experience and exploiting it to influence behavior. This capacity, developed at different rates and in different ways for different people, results in a personality.

\section{Quantity versus quality}

Personality has dimensions of both quantity and quality. The quantity of a personality lies in the amount of experience stored and the variety of processes developed for analyzing what comes in to be stored and for exploiting, consciously or automatically, what is stored. The quality of a personality lies in the relative development of these different qualitative aspects.

A mainly contemplative personality emphasizes conscious analysis, reasoning emphasizes conscious exploitation, perception emphasizes automatic analysis, and reaction emphasizes automatic exploitation. The important point to notice here is that consciousness provides the basis of understanding oneself, though the degree of that understanding comes perhaps more from the quality of analysis and exploitation than from its quantity.

\section{Concerns}

What worries me about videogaming is that it occupies players' perceptions and reactions to the detriment of their contemplation and reasoning and thus hinders self-understanding. Incidentally, excessive indulgence also threatens the physical health of the players (www.theage.com.au/national/ hightech-link-to-teen-sleep-health20080818-3xnk.html).

Continued on page 98 
Videogaming, and similar activities such as casino gambling, not only hinder self-understanding but do so addictively. Several countries have set up clinics that try to cure such addictions. There are, to some eyes at least, few sadder sights than wandering through rooms filled with electronic gaming machines in use late on a Saturday night.

Television has been, and still is, detrimental in overloading perception. Sociologists often blame parents' use of TV to occupy their young for the severe mental underdevelopment of children starting school in the poor areas of economically developed countries. Videogaming's commercial success has sprung from success in providing visual stimulation that provokes swift reaction. The more such stimulation and reaction, the less room for contemplation and reasoning. This trend will become even more compelling: Soon we will have three-dimensional visual displays (www.theage.com.au/news/ biztech/3d-tv-without-the-goggles/ 2008/09/03/1220121308970.html) and even tactile displays (http:// news.bbc.co.uk/2/low/technology/ 7593444.stm).

\section{UNDERSTANDING THINGS}

Concern about the effects of videogaming largely involves how it might influence young people's upbringing given that they are the predominant players. Countering the effects could thus be seen as parents' and teachers' responsibility, aided by digital technology (The Profession, Mar. 2008, pp. 104, 102-103.

\section{Stupidifying}

A recent, widely syndicated and disturbing essay by author Nicholas Carr strongly suggested that the danger from digital technology is far wider and more serious ("Is Google Making Us Stupid?"; www.theatlantic. com/doc/200807/google). Of himself, he says that "what the net seems to be doing is chipping away my capacity for concentration and contemplation" and he goes on to quote quite a few people with similar observations.

This development affects others besides authors and casual online readers like Carr. He mentions a five-year research program about the use of two popular research websites that "found that people using the sites exhibited 'a form of skimming activity,' hopping from one source to another and rarely returning to any source they'd already visited."

\section{Videogames substitute an}

oxymoronic virtual reality

for a real reality, often the

play is confrontational if not

\section{antisocial and violent.}

James Evans, a University of Chicago sociologist, has "found that as more journals become available online, fewer articles are being cited in the reference lists of the research papers published within them. Moreover, those articles that do get a mention tend to have been recently published themselves" (www.economist.com/ science/PrinterFriendly.cfm?story_ id $=11745514$ ).

\section{Reading impaired}

The Internet's digital technology seems to be replacing the understanding of things and issues that comes from contemplation and reasoning with a kind of nonparticipative transmission of facts. Carr quotes Maryanne Wolf, a developmental psychologist at Tufts University: "When we read online," she says, "we tend to become "mere decoders of information.' Our ability to interpret text, to make the rich mental connections that form when we read deeply and without distraction, remains largely disengaged.”
This bodes ill for academic excellence. It also affects student learning as their essays are now popularly patched together from the Web or outsourced over the Internet.

It bodes ill for popular learning as well because much Web content is informal and potentially misleading, if not simply false (www. theage.com.au/news/perspectives/ truth-trash-and-the-internet/2008/ 09/08/1220857455486.html). Reliable sources such as I cite here are very much in the minority.

\section{HUMAN UNDERSTANDING}

In summary, the outward effect of modern digital technology on mental life has been to make an enormous amount of materialtextual, audible, and visual-available to those wealthy enough to afford using the Internet and devices like computers and mobile phones. The ready availability of this material can flood users' perceptions and dominate their daily life. The effects are several.

\section{Virtual versus real}

Videogames substitute an oxymoronic virtual reality for a real reality. Players interact with a digital machine, and, if there are other players, they hide behind so-called avatars. Often the play is confrontational if not antisocial and violent, which can lead to similar behavior in real life. For example, Grand Theft Auto IV was banned in Thailand after a teenager tried to find out if it was as easy to rob a taxi in real life as in the game. He killed the driver (http://news.bbc.co.uk/ newsbeat/low/technology/newsid 7540000/7540623.stm).

The Web makes socially harmful material such as pornography readily available. In Victoria, an Australian state with a population of about five million, about 10,000 children aged 10 to 14 have been cautioned by police, arrested, or ordered to appear in court in the past year, a surge in youth crime that police attribute to children's 
growing exposure to sexual and violent images on the Internet (www.theage.com.au/national/ net-blamed-as-10000-kids-turn-tocrime-20080802-3p00.html).

\section{Antisocial behavior}

The Web has sites intended for "social" use where the sociality is necessarily indirect. Without direct interaction, users can pretend to be other than they really are, as in videogames. One effect of this is to enable sexual predation.

There are even legal effects. In the US, a legal procedure called e-discovery can be used in common law litigation to so greatly increase court costs that the result is determined by wealth (www.economist. com/business/PrinterFriendly.cfm? story_id=12010377). E-discovery requires all the digitally stored material that might be relevant to be made available for search.

These examples imply that digital technology is molding social relationships in antisocial ways. As a consequence, face-to-face social interaction, when it occurs, tends to be competitive rather than cooperative, based on satisfying individual needs regardless of its effect on other people. Other people are seen as threats and constraints rather than as potential friends.

\section{Sonic rage}

One conspicuous area of social confrontation comes from the digital storing and production of what is loosely called music. Many people of the modern perceptual culture require their music to be played loudly anywhere at any time. Some cars that pass by in the street emitting loud thumping even though their windows are closed have a sticker on their back window proclaiming that "If the musics [sic] too loud your [sic] too old." A recent story from England told of a teenage girl on a bus repeatedly kicking an adult who asked her to turn her music down (www.guardian. co.uk/commentisfree/2008/aug/28/ youngpeople/print).

The problem seems to be an inability to relate to other people, particularly people of different cultures, socially and equably. Simply put, this is a lack of human understanding and human social values.

It would be a mistake to see these problems as a failure to maintain a glorious past of social welfare (www. guardian.co.uk/commentisfree/ 2008/aug/01/britishidentity/print). Nevertheless the present is hardly glorious when, for example, one in three young people in English cities

\section{It is a mistake to see social}

problems caused by misuse

of digital technology

and then not take action

to remove those problems.

see it as acceptable to carry a knife in public for self-defense (www. guardian.co.uk/uk/2008/may/18/ ukcrime1).

It is a mistake to see social problems caused by misuse of digital technology and then not take action to remove those problems, especially when that same digital technology could be used as a very effective instrument to help in that removal.

\section{IMPERILED YOUTH}

The preceding discussion relates primarily to conditions and events in what we loosely call developed countries. Modern digital technology is, however, available worldwide, both through the distribution of digital machinery and through Internet connections. China now has more Internet users than the US, and Internet use is growing rapidly in many developing countries (www.economist.com/ printedition/PrinterFriendly.cfm? story_id=11999307).

At this stage, much Internet usage in poorer parts of the world occurs via mobile phones, often at the level of text messages. This can be beneficial to Third World people who can access such services. Indeed, the development of cheap but powerful mobile phones will mean that within a few years the majority of personal Internet and Web traffic will flow through such devices.

However, the significant danger is that once the Internet and Web become so much more widely used through cheap mobile devices, the many more people using them, particularly the young, could become less understanding. In less-developed communities, where personal relationships are more crucial to daily life, lessened understanding could be disproportionately harmful.

While increased use of digital technology in poorer countries might serve to bring their living conditions closer to those in the developed world, one potential benefit is even more important. The adverse effects of climate change will be greater in poorer countries such as Bangladesh, and digital technology will be needed both to help them cope with climate change and to improve the help that more developed countries must give to them.

$\mathbf{W}$ hen discussing digital technology we must remember that technology itself does not accomplish anything nor can it be solely responsible for anything. Such accomplishment comes from the technicians and professionals who carry out this work and are responsible for its results. For computing professionals, their professional society requires them to seek the best social results from their work.

Neville Holmes is an honorary research associate at the University of Tasmania's School of Computing and Information Systems. Contact him at neville.holmes@utas.edu.au. 